\title{
Detection of Brucella abortus by immunofluorescence assay using anti outer membrane protein of $19 \mathrm{kDa}$ antibody
}

\author{
Elham Mohammadi ${ }^{1, A, C, D}$, Mehdi Golchin ${ }^{2, A, D-F}$ \\ ${ }^{1}$ Division of Microbiology, Department of Pathobiology, Faculty of Veterinary Medicine, Shahid Bahonar University of Kerman, Iran \\ ${ }^{2}$ Department of Pathobiology, Faculty of Veterinary Medicine, Shahid Bahonar University of Kerman, Iran \\ A - research concept and design; $\mathrm{B}$ - collection and/or assembly of data; $\mathrm{C}$ - data analysis and interpretation; \\ $D$ - writing the article; $E$ - critical revision of the article; $F$ - final approval of the article
}

Address for correspondence

Elham Mohammadi

E-mail:elham_mohammadidamaneh@yahoo.com

\section{Funding sources}

This investigation was supported by grant No. 96003341 from Iran National Science Foundation (INSF).

Conflict of interest

None declared

Received on December 25, 2016

Reviewed on January 18, 2017

Accepted on February 6, 2018

\begin{abstract}
Background. Brucellosis in humans is one of the most prevalent zoonotic diseases around the world with more than 500,000 new cases per year. It is a weakening disease that requires long-term antibiotic treatment, often resulting in permanent and disabling consequences. Outer membrane proteins (OMPS) of Brucella, which are non-lipopolysaccharide (LPS) antigens, have been used for the diagnostic kits of brucellosis and vaccine design.
\end{abstract}

Objectives. The aim of this study was to identify Brucella abortus with an immunofluorescence (IF) test using an antibody against recombinant outer membrane protein (OMP) of $19 \mathrm{kDa}$ of this bacterium.

Material and methods. The OMP19 gene of Brucella spp. was synthesized, cloned and expressed in Escherichia coli cells. The OMP19 protein was purified by metal chelate affinity chromatography and subsequently used for the immunization of rabbits to produce a polyclonal antibody. Then, this antibody was conjugated to fluorescein isothiocyanate (FITC) and used for the detection of Brucella by an IF test. Also, the sensitivity and specificity of this antibody for the diagnosis of clinical isolates was calculated.

Results. Outer membrane protein 19 was expressed well and reacted with a commercial antiserum against His-tag in an immunoblot assay. Polyclonal antibodies obtained from the serum of rabbits immunized with the purified protein showed strong reactivity in the enzyme-linked immunosorbent assay (ELISA). Moreover, the polyclonal antibody conjugated to FITC was able to properly identify Brucella abortus. Sensitivity and specificity of this IF test in comparison with a polymerase chain reaction (PCR) assay was $84.2 \%$ and 50\%, respectively.

Conclusions. This high-titer antibody could potentially be valuable for the specific diagnostic test of brucellosis.

Key words: antibody, immunofluorescence assay, OMP19, Brucella abortus

DOI

10.17219/acem/85081

Copyright

Copyright by Author(s)

This is an article distributed under the terms of the

Creative Commons Attribution Non-Commercial License

(http://creativecommons.org/licenses/by-nc-nd/4.0/) 


\section{Introduction}

Brucella spp. are intracellular Gram-negative bacteria that cause human disease and significant economic losses worldwide due to livestock infection. ${ }^{1}$ Lipopolysaccharide (LPS) of Brucella spp. elicits long-term serological reactions in vaccinated and infected animals. ${ }^{1-4}$ In serologic tests, LPS of the bacterial cell membrane has been mainly used to identify particular antibodies. For these reasons, it is difficult to differentiate between infected and vaccinated animals using LPS-based serological tests. ${ }^{5-8}$ Moreover, serological examinations on the basis of the detection of LPS, due to a cross-reaction with other Gram-negative microorganisms, for example Salmonella spp., Escherichia coli and Yersinia enterocolitica O:9, cause false-positive reactions. ${ }^{9-12}$ Outer membrane proteins (OMPs) of Brucella, which are non-LPS antigens, have been used for the diagnostic kits of brucellosis and vaccine design. ${ }^{13-18}$ The Brucella cell wall consists of a peptidoglycan (PG) layer firmly connected with the external layer consisting of at least 75 proteins with several OMPs. ${ }^{19}$ These include the major OMPs of group 2 (porin, 34-40 kDa), group $3(25-30 \mathrm{kDa})$ that was described initially by Dubray and Bezard ${ }^{20}$ and Verstreate et al., ${ }^{21}$ the lipoprotein covalently bound to PG, ${ }^{22,23}$ and the minor OMPs of group 1 (88-94 kDa). The OMPs of Brucella spp. have been widely considered as potentially defensive and immunogenic antigens. ${ }^{24,25}$ Monoclonal antibodies (mAbs) against group 1, 2 and 3 OMPs, as well as mAbs to minor surface-exposed OMPs with molecular masses (MMs) of 10, 16, 19, and 31-34 kDa (the latter is a major OMP in B. melitensis strains but is less abundant in $B$. abortus), have been produced. ${ }^{26}$ Physicochemical and practical examination has recently confirmed that OMP10, OMP16 and OMP19 are lipoproteins that are uncovered at the cell surface. ${ }^{27}$ It has been proven that these lipoproteins are present in several Brucella strains. These strains represent all 6 Brucella species and all their biovars. According to published data, OMP19 is an immunoreactive outer membrane lipoprotein. ${ }^{28-33}$ The appearance of OMP19 has been proven to be necessary for the acceptance of a defensive reaction by the vaccine strain $B$. abortus $\mathrm{S} 19$, since the abrogation of its gene in this strain leads to the destruction of its protective ability in heifers, ${ }^{34}$ showing that OMP19 should be a key component of a subunit vaccine against brucellosis. Furthermore, we have previously reported that recombinant OMP19, when injected with the mucosal adjuvant cholera poison, is a protective mucosal antigen that confers protection against an oral challenge with virulent Brucella. ${ }^{30}$ For this reason, in this research, we expressed OMP19 for the creation of a polyclonal antibody to use it in an immunofluorescence assay (IFA).

The study was endorsed by Animal Experimentation Ethics Committee of Kerman University of Medical Sciences, Iran.

\section{Material and methods}

\section{Cloning and expression}

The OMP19 gene was synthesized based on the existing gene sequence of $B$. abortus (accession No. U35742) and cloned into the pET-28a expression vector by Genray Biotechnology Company (Shanghai, China). The pET-28a vector allowed the expression of the cloned gene as a fusion protein with a 6 -histidine residue at the amino terminus. The recombinant plasmid was transformed into an $E$. coli strain BL21 (DE3) competent cell by the heat shock method $\left(42^{\circ} \mathrm{C}\right.$ for $90 \mathrm{~s}$ ), according to standard protocols. ${ }^{35}$ The transformant bacterium was chosen from Luria Bertani (LB) agar medium containing $30 \mu \mathrm{g} / \mathrm{mL}$ of kanamycin. The transformant was grown in $10 \mathrm{~mL} \mathrm{LB}$ containing $50 \mathrm{mg} / \mathrm{mL}$ kanamycin at $37^{\circ} \mathrm{C}$, shaken at $200 \mathrm{rpm}$ overnight. Then, $1 \mathrm{~mL}$ of the medium was supplemented to $100 \mathrm{~mL}$ of fresh $\mathrm{LB}$. The transformant was grown at $37^{\circ} \mathrm{C}$ until the optical density (OD) at $600 \mathrm{~nm}$ achieved 0.6 , and after being prompted by including Isopropyl- $\beta-D-$ 1-thiogalactopyranoside (IPTG) at a final concentration of $1 \mathrm{mM}$ and incubation at $25^{\circ} \mathrm{C}$ overnight with shaking. The transformant was amassed by centrifugation at $5000 \times \mathrm{g}$ for $10 \mathrm{~min}$, then the cell was resuspended in the (5-pellet volume) lysis buffer pH $8.0(300 \mathrm{mM} \mathrm{NaCl}$, $10 \mathrm{mM}$ Imidazole, $50 \mathrm{mM} \mathrm{NaH}_{2} \mathrm{PO}_{4}$ ) and incubated at $4^{\circ} \mathrm{C}$ for $30 \mathrm{~min}$. The lysate was also sonicated (10 s pulse on followed by $10 \mathrm{~s}$ pulse off, total time: $4 \mathrm{~min}$ ). The resulting lysate was centrifuged at $5000 \times \mathrm{g}$ for $30 \mathrm{~min}$ at $4^{\circ} \mathrm{C}$. The supernatant including the recombinant protein was examined by sodium dodecyl sulfate-polyacrylamide gel electrophoresis (SDS-PAGE), using 5\% stacking and 15\% resolving gels, dot blot and western blot analyses. The recombinant OMP19 was purified using metal chelate affinity chromatography by Ni-NTA column (Qiagen, Hilden, Germany).

\section{Immunization}

A New Zealand white female rabbit was immunized intramuscularly with the purified recombinant OMP19 protein $(0.5 \mathrm{mg} / \mathrm{mL})$ mixed with Freund's complete adjuvant (Sigma-Aldrich, St. Louis, USA) (1:1) administered into the back legs of the rabbit, followed by 2 injections emulsified with Freund's incomplete adjuvant and without adjuvant, respectively, at 2-week intervals.

\section{Antiserum collection}

The rabbit was bled 4 times (before each injection and 2 weeks after the $3^{\text {rd }}$ injection). Blood was obtained from the marginal vein of the ear and kept at $4^{\circ} \mathrm{C}$ overnight. Serum was isolated by centrifugation at $3000 \times \mathrm{g}$ for $10 \mathrm{~min}$ and put away at $-20^{\circ} \mathrm{C}$ until utilized.

To evaluate the serum titer, 2 enzyme-linked immunosorbent assay (ELISA) tests were carried out. In the 
$1^{\text {st }}$ ELISA test, the reaction of serum during immunization against the purified recombinant protein was tested. In the $2^{\text {nd }}$ ELISA test, final serum was diluted from 1/100 until $1 / 100000$ to determine the serum titer.

\section{Enzyme-linked immunosorbent assay}

Sera were assessed by ELISA for antibody reactivity vs the recombinant OMP19 as follows: 96-well polystyrene microtiter plates (Nunc, Roskilde, Denmark) were covered with the recombinant OMP19 $(100 \mu \mathrm{L}$ per well) in phosphate-buffered saline (PBS) (Sigma-Aldrich, St. Louis, USA) at a density of $25 \mu \mathrm{g} / \mathrm{mL}$ and incubated overnight at $4^{\circ} \mathrm{C}$. The wells were washed 3 times with PBS and blocked with $200 \mu \mathrm{L}$ of blocking buffer PBS containing $3 \%$ bovine serum albumin (BSA) (Sigma-Aldrich) for $2 \mathrm{~h}$ at $37^{\circ} \mathrm{C}$. After 3 washes, the diluted sera were added and the plates were incubated for $1 \mathrm{~h}$ at $37^{\circ} \mathrm{C}$. The plates were then washed 3 times with $0.1 \%(\mathrm{v} / \mathrm{v})$ Tween-20 in PBS (PBST). Antibodies attaching to OMP19 were visualized using $100 \mu \mathrm{L}$ polyclonal goat peroxidase-conjugated anti-rabbit IgG (Bio-Rad Laboratories, Inc., Hercules, USA) diluted 15,000-fold in blocking buffer. After 1-h incubation at $37^{\circ} \mathrm{C}$, the plates were washed with PBST and developed with $100 \mu \mathrm{L}$ of 3,3',5,5'-tetramethylbenzidine (TMB) substrate $(1 \mathrm{~mL}$ TMB, $9 \mathrm{~mL}$ of citrate-phosphate buffer, $\mathrm{pH} 5$, and $3 \mu \mathrm{L}$ of $30 \% \mathrm{H}_{2} \mathrm{O}_{2}$ ). The reaction was stopped after $15 \mathrm{~min}$ by the addition of $50 \mu \mathrm{L} 1.0 \mathrm{M} \mathrm{H}_{2} \mathrm{SO}_{4}$ to each well and read at $450 \mathrm{~nm}$ by the ELISA plate reader.

\section{Immunofluorescence test}

The polyclonal antibody was purified using the Proteus Protein Mini Purification Spin Column Pack (Bio-Rad Laboratories, Inc., Hercules, USA). The antibody was conjugated to fluorescein isothiocyanate (FITC) using standard protocols. Briefly, $40 \mu \mathrm{L}$ of antibody $(100 \mu \mathrm{g} / \mathrm{mL})$ was mixed with $80 \mu \mathrm{L}$ of borate buffer $(0.1 \mathrm{M})$. Then, $4 \mu \mathrm{L}$ of FITC $(1 \mathrm{mg} / \mathrm{mL})$ was added to $120 \mu \mathrm{L}$ of the mixture and incubated at $37^{\circ} \mathrm{C}$ for $30 \mathrm{~min}$. The conjugated antibody was stored at $4^{\circ} \mathrm{C}$ until use.

The detection of B.abortus by IFA: The amount of $500 \mu \mathrm{L}$ of culture medium, which included B. abortus, E. coli, Salmonella, and Klebsiella (negative controls), was centrifuged at $4000 \times \mathrm{g}$ for $10 \mathrm{~min}$. The resulting pellets were washed 3 times with PBS and suspended in $200 \mu \mathrm{L}$ of PBS. Then, $20 \mu \mathrm{L}$ of the conjugated antibody was added and the suspensions were incubated at room temperature overnight with shaking. Subsequently, the suspensions were centrifuged, washed 3 times with PBS, and then $10 \mu \mathrm{L}$ of the samples were examined under a fluorescence microscope.

In this study, 29 bacterial isolates including 19 Brucella isolates, confirmed with specific primers in the polymerase chain reaction (PCR), and 10 non-Brucella isolates without a specific amplicon in the PCR, were used to determine the sensitivity and specificity of the above-mentioned immunofluorescence (IF) test, using the anti-OMP19 antibody.
The results of variables, including truly positive (TP), truly negative (TN), false positive (FP), and false negative (FN) ones, were analyzed using the following formulas:

$$
\begin{aligned}
& \text { Sensitivity }=[\mathrm{TP} /(\mathrm{TP}+\mathrm{FN})] \times 100 \\
& \text { Specificity }=[\mathrm{TN} /(\mathrm{TN}+\mathrm{FP})] \times 100
\end{aligned}
$$

\section{Results}

\section{Expression and purification}

The induced transformant was examined using SDSPAGE and immunoblotting. The SDS-PAGE examination of extracted total proteins indicated that OMP19 was expressed successfully with an estimated molecular weight of $19 \mathrm{kDa}$ (Fig. 1, 2). The protein was transferred to the nitrocellulose membrane and the specificity of the expressed $6 \times$ His-tagged recombinant OMP19 protein was determined using a commercial anti-His-tag antibody (Sigma-Aldrich, St. Louis, USA) by an immunoblot assay (Fig. 3, 4). The recombinant protein was purified with an affinity chromatography and subsequently used for the immunization of the rabbit.

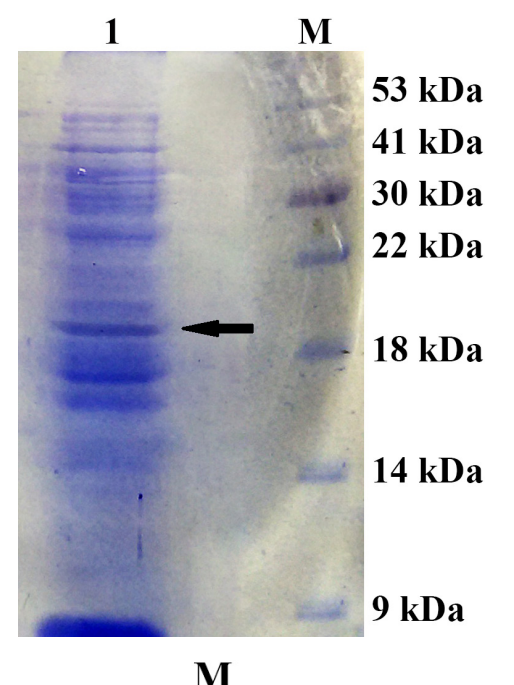

Fig. 1. SDS-PAGE analysis of total cell lysate of $E$. coli producing the OMP19 protein

OMP19 - the recombinant outer membrane protein 19 kDa; lane 1 - OMP19; lane M - protein prestained ladder the arrowhead shows the location of the Brucella recombinant protein.

Fig. 2. SDS-PAGE analysis of the purified recombinant Brucella OMP19 protein
OMP19 - the recombinant outer membrane protein 19 kDa; lane $M$ - protein prestained ladder.
93 kDa
$70 \mathrm{kDa}$
$53 \mathrm{kDa}$

$41 \mathrm{kDa}$

30 kDa

$22 \mathrm{kDa}$

18 kDa

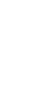




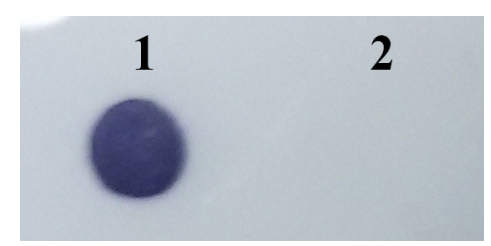

Fig. 3. Dot blot analysis of the expressed His-tagged OMP19 protein, using a commercial anti-His-tag peroxidaseconjugated antibody

OMP19 - the recombinant outer membrane protein 19 kDa; lane 1 - OMP19; lane 2 negative control.

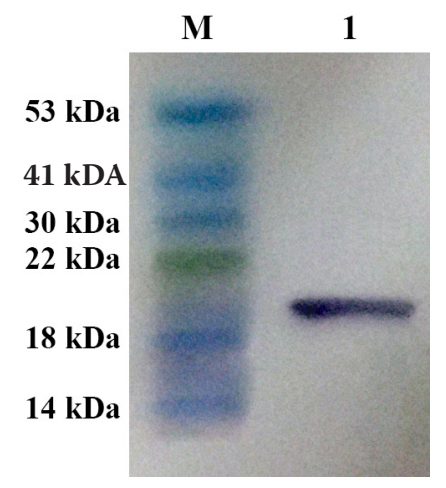

Fig. 4. Western blot analysis of the expressed His-tagged OMP19 protein, using a commercial antiHis-tag peroxidase-conjugated antibody

OMP19 - the recombinant outer membrane protein $19 \mathrm{kDa}$; lane 1 - OMP19; lane M - protein prestained ladder.

\section{Production of a polyclonal antibody}

The immunization of a New Zealand white female rabbit led to the production of a specific polyclonal antibody against the OMP19 protein. As Fig. 5 shows, during the immunization procedure the titer of the antibody against this protein rose gradually. Figure 6 indicates that a high affinity antibody with a strong reaction was achieved after the last immunization.

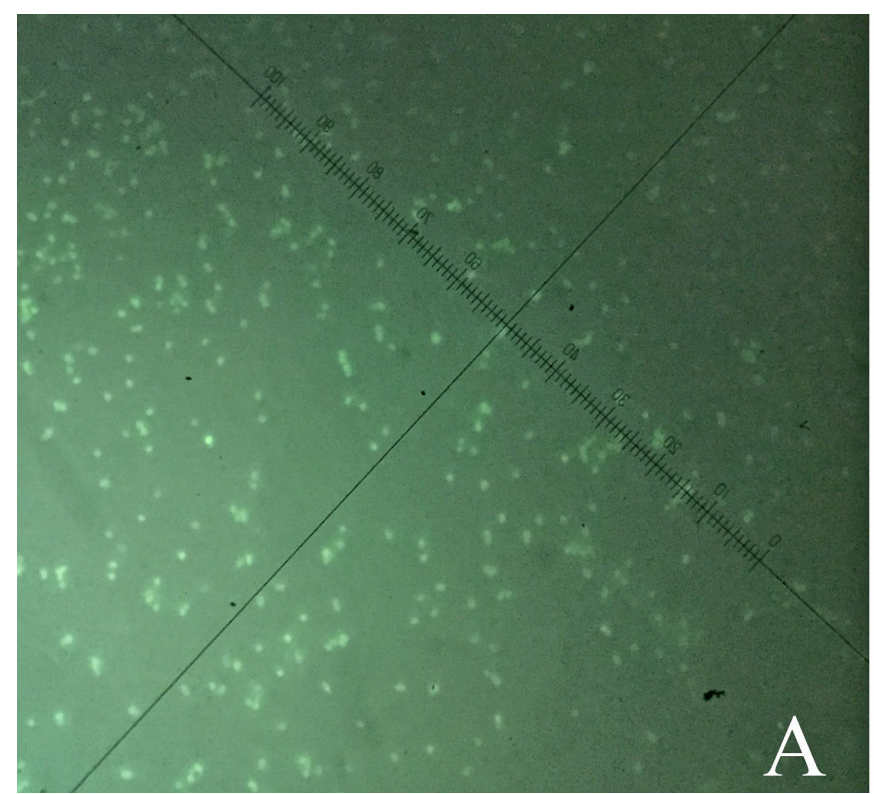

Fig. 7. Recognition of Brucella with a fluorescence microscope

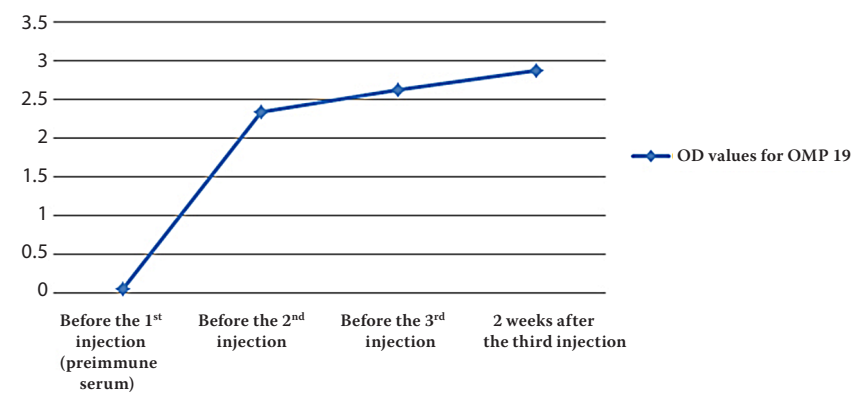

Fig. 5. The production of the polyclonal antibody against the recombinant outer protein $19 \mathrm{kDa}$ (OMP19) of Brucella spp. during the immunization of a rabbit by the enzyme-linked immunosorbent assay (ELISA)

OD - optical density.

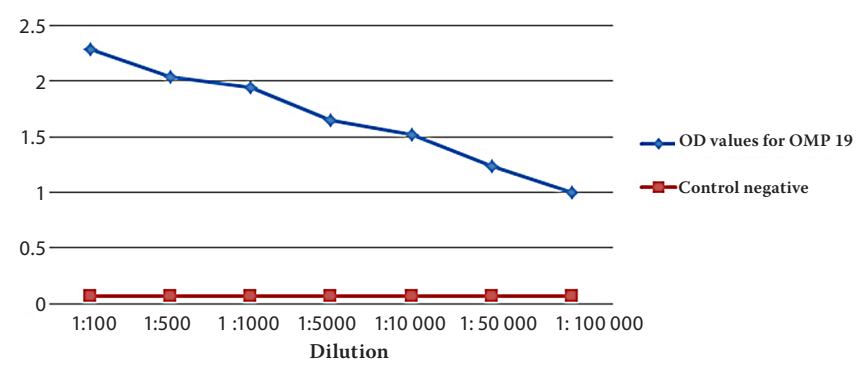

Fig. 6. Determination of the titer of the polyclonal antibody by the enzyme-linked immunosorbent assay (ELISA)

OD - optical density.

\section{Recognition of Brucella with a fluorescence microscope}

The anti-OMP19 polyclonal antibody conjugated to FITC was able to properly identify B. abortus, while the negative controls were not identified (Fig. 7). In evaluating sensitivity and specificity, 16 of 19 Brucella isolates and 5 of 10 non-Brucella isolates were IF-positive in the test. Therefore, the sensitivity and specificity of this test were $84.2 \%$ and $50 \%$, respectively.

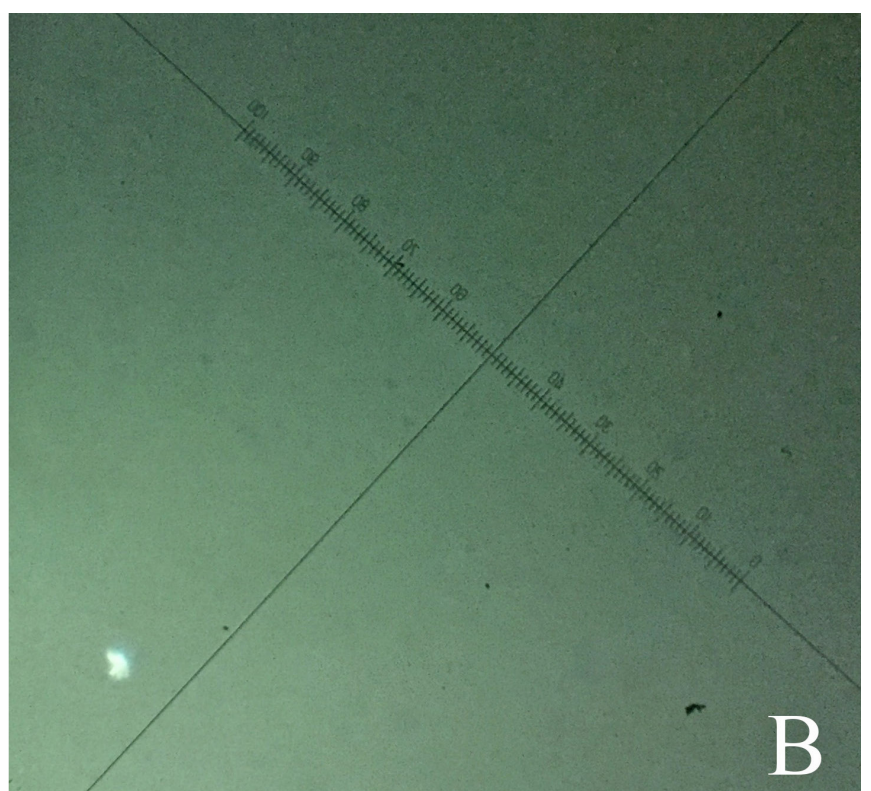

A - B. abortus; B - negative controls. 


\section{Discussion}

The diagnosis of brucellosis by serological examinations on the basis of the detection of antibodies against LPS of bacterial cell membranes causes false positive results in some cases because of cross-reactivity with other Gram-negative microorganisms. The OMPs of Brucella spp. have been widely considered as potential immunogenic and protective antigens.

In this research, 1 OMP of Brucella, a non-LPS group of immunogens, was used. The OMP19 was expressed as a fusion protein containing $6 \times$ His-tag. The recombinant OMP19 reacted positively with the antibody against Histag in blotting assays. The immunization of a New Zealand white female rabbit by the recombinant OMP19 led to a high-titer polyclonal antibody, as showed in ELISA. The high-titer polyclonal antibody can be utilized for experimental biology, medicine, biomedical research, the development of a vaccine and improved diagnostic tests. Some other investigators have previously produced particular antibodies vs several OMPs of Brucella. For example, several mAbs to 7 Brucella outer membrane proteins were considered by Cloeckaert. ${ }^{14}$ These antibodies were achieved by vaccinating mice with sodium dodecyl sulfateinsoluble (SDS-I) portions, cell walls, or whole bacterial cells of $B$. melitensis or B. abortus. The OMPs detected by these antibodies were the proteins with a molecular weight of $25-27 \mathrm{kDa}$ and $36-38 \mathrm{kDa}$ (porin) (major proteins), and the proteins with a molecular weight of 10, 16.5, $19,31-34$, and $89 \mathrm{kDa}$ (minor proteins). ${ }^{26}$

The production of an mAb against OMPs with a molecular mass of 25-27 kDa (Ba-4, Ba-5), 36-38 kDa (Ba-6) of B. abortus S99 and rOMP31 of goat Brucella was performed by Farshad et al. and Zheng et al. ${ }^{36,37}$ It was proven by Ghasemi et al. that the immunized serum was achieved from a rabbit that was inoculated with attenuated B. melitensis. This serum contained antibodies against recombinant OMP31 (rOMP31). ${ }^{38}$ The production of antibodies against OMPs of B. ovis in rams was performed by RiezuBoj et al. ${ }^{39}$ The production of immunoglobulins was investigated by Sung et al. in BALB/c immunized with $\mathrm{Cu} / \mathrm{Zn}$ superoxide dismutase (SOD1) and OMP2b porin of B. abortus. ${ }^{40}$ The production of an antibody against the minor 89-kDa OMP of Brucella in cattle was performed by Limet et al. ${ }^{41}$ Western immunoblot analysis using antisera raised against 3 strains of B. abortus, i.e., RB 51, S19 and a local field isolate of biotype 1 in buffaloes, indicated the production of antibodies against OMPs in a study by Munir et al. ${ }^{42}$ On the basis of previous studies, it can be stated that OMPs of Brucella are capable of inducing an immune response and antibody production. These antibodies can be utilized for the improvement of vaccine candidates and diagnostic tests of brucellosis.

The antibody produced against the recombinant OMP19 had a high titer. Therefore, it could be utilized for diagnostic tests of brucellosis and the improvement of vaccine candidates for humans and animals. Moreover, this antibody conjugated to FITC was able to properly identify B. abortus. Therefore, it could be used for diagnostic tests of brucellosis in humans and animals. Although the sensitivity of antibodies was high, their specificity was moderate in an IF test. This could be due to some cross-reactions of the polyclonal antibody.

\section{References}

1. Baldi PC, Giambartolomei GH, Goldbaum FA, et al. Humoral immune response against lipopolysaccharide and cytoplasmic proteins of Brucella abortus in cattle vaccinated with B. abortus S19 or experimentally infected with Yersinia enterocolitica serotype 0:9. Clin Diagn Lab Immunol. 1996;3:472-476.

2. De Bagüés MJ, Marin C, Blasco J, Moriyon I, Gamazo C. An ELISA with Brucella lipopolysaccharide antigen for the diagnosis of B. melitensis infection in sheep and for the evaluation of serological responses following subcutaneous or conjunctival B. melitensis strain Rev 1 vaccination. Vet Microbiol. 1992;30:233-241.

3. Raybould T. Antigens of diagnostic significance in Brucella abortus. Can J Microbiol. 1982;28:557-566.

4. Watarai M, Kim S, Yamamoto J, et al. A rapid agglutination assay for canine brucellosis using antigen coated beads. J Vet Med Sci. 2007;69:477-480.

5. Corbel M. Recent advances in brucellosis. J Med Microbiol. 1997;46:101-103.

6. Delpino MV, Estein SM, Fossati CA, Baldi PC, Cassataro J. Vaccination with Brucella recombinant DnaK and SurA proteins induces protection against Brucella abortus infection in BALB/c mice. Vaccine. 2007;25:6721-6729.

7. Morgan W, MacKinnon D, Lawson J, Cullen G. The rose bengal plate agglutination test in the diagnosis of brucellosis. Vet Rec. 1969;85:636-641.

8. Ruiz-Mesa J, Sánchez-Gonzalez J, Reguera J, Martin L, Lopez-Palmero S, Colmenero J. Rose Bengal test: Diagnostic yield and use for the rapid diagnosis of human brucellosis in emergency departments in endemic areas. Clin Microbiol Infect. 2005;11:221-225.

9. Christopher S, Umapathy B, Ravikumar K. Brucellosis: Review on the recent trends in pathogenicity and laboratory diagnosis. J Lab Physicians. 2010;2:55.

10. Eskra L, Canavessi A, Carey M, Splitter G. Brucella abortus genes identified following constitutive growth and macrophage infection. Infect Immun. 2001;69:7736-7742.

11. Lindler $\mathrm{LE}$, Hadfield TL, Tall BD, et al. Cloning of a Brucella melitensis group 3 antigen gene encoding Omp28, a protein recognized by the humoral immune response during human brucellosis. Infect Immun. 1996;64:2490-2499.

12. Smirnova EA, Vasin AV, Sandybaev NT, et al. Current methods of human and animal brucellosis diagnostics. Adv Infect Dis. 2013;3:177-184.

13. Cloeckaert A, Baucheron S, Vizcaino N, Zygmunt MS. Use of recombinant BP26 protein in serological diagnosis of Brucella melitensis infection in sheep. Clin Diagn Lab Immunol. 2001;8:772-775.

14. Cloeckaert A, Jacques I, Bosseray N, et al. Protection conferred on mice by monoclonal antibodies directed against outer-membrane-protein antigens of Brucella. J Med Microbiol. 1991;34:175-180.

15. de Bagüés MJ, Elzer P, Blasco J, Marin C, Gamazo C, Winter A. Protective immunity to Brucella ovis in BALB/c mice following recovery from primary infection or immunization with subcellular vaccines. Infect Immun. 1994;62:632-638.

16. Ficht TA, Bearden S, Sowa B, Adams L. A 36-kilodalton Brucella abortus cell envelope protein is encoded by repeated sequences closely linked in the genomic DNA. Infect Immun. 1988;56:2036-2046.

17. Gupta V, Kumari R, Vohra J, Singh S, Vihan V. Comparative evaluation of recombinant BP26 protein for serological diagnosis of Brucella melitensis infection in goats. Small Rumin Res. 2010;93:119-125.

18. Ko KY, Kim JW, Her M et al. Immunogenic proteins of Brucella abortus to minimize cross reactions in brucellosis diagnosis. Vet Microbiol. 2012;156:374-380.

19. Sowa B, Kelly K, Ficht T, Frey M, Adams L. SDS-soluble and peptidoglycan-bound proteins in the outer membrane-peptidoglycan complex of Brucella abortus. Vet Microbiol. 1991;27:351-369. 
20. Dubray G, Bezard G. Isolation of three Brucella abortus cell-wall antigens protective in murine experimental brucellosis. Ann Rech Vet. 1980;11:367-373.

21. Verstreate D, Creasy M, Caveney N, Baldwin C, Blab M, Winter A. Outer membrane proteins of Brucella abortus: Isolation and characterization. Infect Immune. 1982;35:979-989.

22. Gomez-Miguel MJ, Moriyon I. Demonstration of a peptidoglycanlinked lipoprotein and characterization of its trypsin fragment in the outer membrane of Brucella spp. Infect Immune. 1986;53:678-684.

23. Gomez-Miguel MJ, Moriyon I, Lopez J. Brucella outer membrane lipoprotein shares antigenic determinants with Escherichia coli Braun lipoprotein and is exposed on the cell surface. Infect Immune. 1987;55:258-262.

24. Cassataro J, Pasquevich KA, Estein SM, et al. A DNA vaccine coding for the chimera BLSOmp31 induced a better degree of protection against $B$. ovis and a similar degree of protection against $B$. melitensis than Rev. 1 vaccination. Vaccine. 2007;25:5958-5967.

25. Cloeckaert C, Jacques I, Limet J, Dubray G. Immunogenic properties of Brucella melitensis cell-wall fractions in BALB/c mice. J Med Microbiol. 1995;42:200-208.

26. Cloeckaert A, De Wergifosse P, Dubray G, Limet J. Identification of seven surface-exposed Brucella outer membrane proteins by use of monoclonal antibodies: Immunogold labeling for electron microscopy and enzyme-linked immunosorbent assay. Infect Immune. 1990;58:3980-3987.

27. Tibor A, Decelle B, Letesson J-J. Outer membrane proteins Omp10, Omp16, and Omp19 of Brucella spp. are lipoproteins. Infect Immune. 1999;67:4960-4962.

28. Farahi F, Asli E, Mobarez AM, Khoramabadi N, Bakhtiari A. Recombinant Brucella abortus outer membrane protein 19 (rOmp19) significantly stimulates splenic lymphocytes of immunized BALB/c mice. Afr J Microbiol Res. 2012;6:4128-4131.

29. Giambartolomei GH, Zwerdling A, Cassataro J, Bruno L, Fossati CA Philipp MT. Lipoproteins, not lipopolysaccharide, are the key mediators of the proinflammatory response elicited by heat-killed Brucella abortus. J Immunol. 2004;173:4635-4642.

30. Pasquevich KA, Estein SM, Samartino CG, et al. Immunization with recombinant Brucella species outer membrane protein Omp16 or Omp19 in adjuvant induces specific CD4+ and CD8+ T cells as well as systemic and oral protection against Brucella abortus infection. Infect Immune. 2009;77:436-445.
31. Pasquevich KA, IbañezAE, Coria LM, et al. An oral vaccine based on U-Omp19 induces protection against B. abortus mucosal challenge by inducing an adaptive IL-17 immune response in mice. PLoS One. 2011;6:e16203.

32. Sidhu-Munoz RS, Sancho P, Vizcaino N. Brucella ovis PA mutants for outer membrane proteins Omp10, Omp19, SP41, and BepC are not altered in their virulence and outer membrane properties. Vet Microbiol. 2016;186:59-66.

33. Tibor A, Saman E, de Wergifosse P, Cloeckaert A, Limet JN, Letesson JJ. Molecular characterization, occurrence, and immunogenicity in infected sheep and cattle of two minor outer membrane proteins of Brucella abortus. Infect Immun. 1996;64:100-107.

34. Fiorentino MA, Campos E, Cravero S, et al. Protection levels in vaccinated heifers with experimental vaccines Brucella abortus M1-luc and INTA 2. Vet Microbiol. 2008;132:302-311.

35. Sambrook J, Russell DW. Molecular Cloning: A Laboratory Manual. $3^{\text {rd }}$ ed. New York, NY: Coldspring-Harbour Laboratory Press; 2001.

36. Farshad S, Mehrabanpour M, Namavari M, Hosseini S, Tavakkoli A, Ghaderi A. Production and characterization of monoclonal antibodies against Brucella abortus S (99) surface antigens. Iran Biomed J. 2002;6:7-12.

37. Zheng W, Wang Y, Zhang Z, Yan F. Immunological characteristics of outer membrane protein omp31 of goat Brucella and its monoclonal antibody. Genet Mol Res. 2015;14:11965.

38. Ghasemi A, Salari MH, Zarnani AH, et al. Immune reactivity of Brucella melitensis-vaccinated rabbit serum with recombinant Omp31 and DnaK proteins. Iran J Microbiol. 2013;5:19-23.

39. Riezu-Boj Jl, Moriyon I, Blasco J, Gamazo C, Diaz R. Antibody response to Brucella ovis outer membrane proteins in ovine brucellosis. Infect Immune. 1990;58:489-494.

40. Sung KY, Jung M, Shin MK, et al. Induction of immune responses by two recombinant proteins of Brucella abortus, outer membrane proteins $2 \mathrm{~b}$ porin and $\mathrm{Cu} / \mathrm{Zn}$ superoxide dismutase, in mouse model. J Microbiol Biotechnol. 2014;24:854-861.

41. Limet J, Cloeckaert A, Bezard G, Van Broeck J, Dubray G. Antibody response to the $89-\mathrm{kDa}$ outer membrane protein of Brucella in bovine brucellosis. J Med Microbiol. 1993;39:403-407.

42. Munir R, Afzal M, Hussain M, Naqvi S, Khanum A. Outer membrane proteins of Brucella abortus vaccinal and field strains and their immune response in buffaloes. Pak Vet J. 2010;30:110-114. 